\title{
Refined Assessment Technique in Engineering Education Based on Response from Stake-holders
}

\author{
Deepesh S Kanchan ${ }^{1}$, Franco Aldrin Menezes ${ }^{2}$, Rolen Lionel Rodrigues ${ }^{3}$ \\ ${ }^{1}$ Electrical \& Electronics Engineering Department, St Joseph Engineering College, Mangalore, Karnataka \\ ${ }^{2}$ Electrical \& Electronics Engineering Department, St Joseph Engineering College, Mangalore, Karnataka \\ ${ }^{3}$ Electrical \& Electronics Engineering Department, St Joseph Engineering College, Mangalore, Karnataka \\ 1deepeshk@sjec.ac.in \\ francom@sjec.ac.in \\ rolenr@sjec.ac.in
}

\begin{abstract}
In recent literature on Engineering Education research, a significant amount of knowledge is shared on the effective design of Holistic and Analytic rubrics for Assessment. Although the designed rubrics are shared with the students, fair and consistent assessment of student performance cannot be ensured since the rubrics designed by the course instructor have not been validated by stakeholders like students from the previous batch who have taken the course, Alumni, and Industry. This study explores the refinement techniques for redesigning the assessment rubrics. The paper puts to test an Analytical rubric by taking relevant feedback from the stake-holders. The method of survey-based statistical analysis was adopted in redesigning the rubrics. A total of 188 students were asked to take up this survey. These participants included $70 \%$ of students from the Undergraduate Engineering background, 20\% Alumni, and $10 \%$ industrial stake-holders.

The findings of the survey and the ensuing statistical analysis prove that the stake-holders can actively take part in redesigning assessment rubrics by giving valuable feedback on rubrics criteria which are judgmental, qualitative and can lead to an inconsistent assessment of student performance. The survey was aimed at redesigning rubrics for assessment of online written assignments during the COVID crisis period. It was observed that the majority of students agreed with the quantitative criteria of the rubrics. Valid suggestions given by students on improving the qualitative criteria were incorporated in the new design.
\end{abstract}

Keywords: Rubrics Design, Assessment, Stake-holders, Assignment.

\section{Introduction}

The thought of assessing learnings made by students in any class invariably strikes a teacher. This assessment has to be effectively conducted to ensure fair and consistent assessments. The strategies chosen for assessment may vary from one course to the other, but the strategy adopted should assure justice to the learning made by each student. The criteria on which such assessments are done must be meticulously designed and reviewed.

\section{Corresponding Author}

Deepesh S K, Department of Electrical \& Electronics Engineering, St Joseph Engineering College. Mangaluru deepeshk@sjec.ac.in

The chosen criteria may be applied on an analytical or Holistic scale to create the rubrics for assessment. Since the rubrics can decide the final grade points of the students, the design process should comply with recent literature on Rubrics design (B. Surendra Reddy 2015). The selection of criteria for rubrics can be made on experience of course Instructors handling similar courses, Alumni, and student feedback. The rubrics designed by a course Instructor must be peer-reviewed for better clarity on the selection of criteria and assigned weights. The rubrics should be verified and validated through multiple channels (Smt. Soniya Agrawal and Dr. Chandasree Das 2015). Such validations are required since rubrics is the core ingredient in any assessment strategy. The validation can be independently done to ensure the impartial refinement of rubrics. Refined and validated rubrics is the hallmark of a robust assessment strategy with no glitches and errors. Shortcomings in rubrics design can cause unfair and inconsistent assessment which leads to irreparable damage to student-teacher relationships. A course instructor needs to refine and validate the assessment rubrics through feedback from stake-holders like alumni, industry, parents, etc. A negligible amount of time needs to be spared by each course instructor for rubrics refinement at the start of every active semester. This investment of time has yielded appreciable improvement in the academic performance of students as shown by case studies done in the courses of Electrical \& Electronics Engineering, St Joseph Engineering College. Refinement of Rubrics could mean alterations in proposed criteria, addition or removal of criteria, minor modifications in definition of rubrics criteria, and scaling up or scaling down of weightage given to criteria(Dr. Shreeranga Bhat et al 2020, S.B. Sangle et al 2020) . Such refinement standards are essential in normal and days of emergency like a pandemic to ensure the enhancement of student faith in the assessment system and its consequences.

\section{Methodology}

The process/methodology adopted for refining rubrics for evaluation is shown in Figure 1. Rubrics refinement is done at the beginning of every semester for evaluating simple or complex problems. A simple evaluation could mean assessing lab records on a weekly basis or evaluation rubrics for assessing the performance of a student in class or in the laboratory. A complex evaluation could mean evaluation of project work spread over one or two semesters having composite characteristics such as observation of experimental results evaluation of analysis and design done by students, evaluation of written and oral presentation by 
student groups. Such complex evaluations may include assessment of group and individual performance and needs to be accurate and consistent. Such rigorous evaluations need rubrics that are robust in nature and can address the concerns of teachers and students. Even simple evaluations for written assignments in the online mode of teaching during periods of a pandemic can be tricky and needs careful refinement to satisfy all stakeholders.

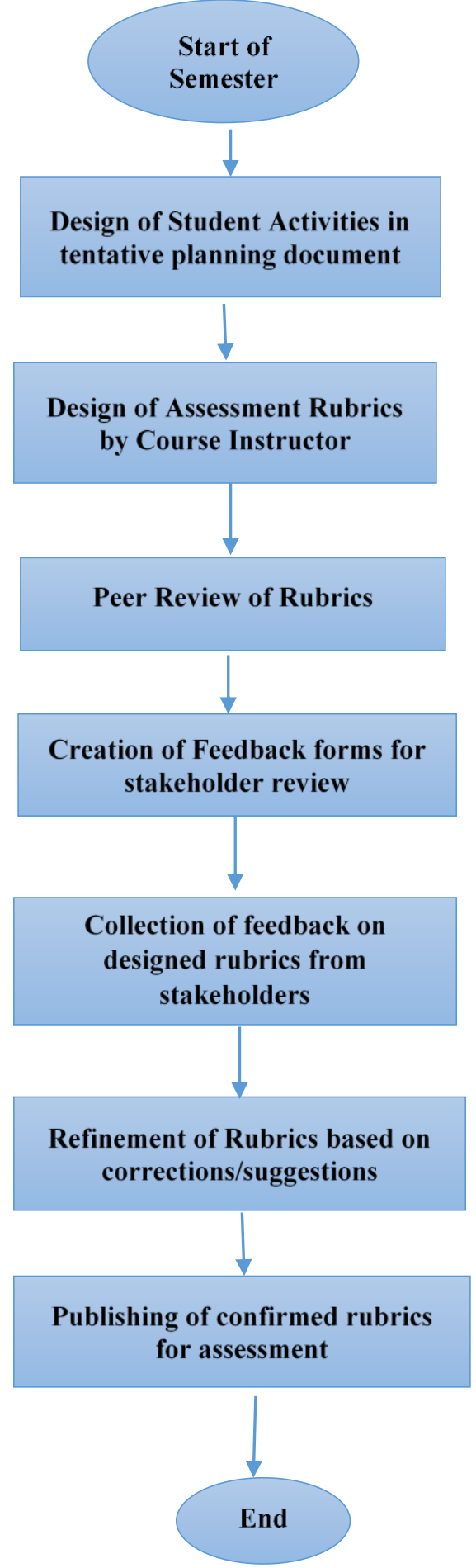

Figure 1: Flow chart of rubrics refinement

At the commencement of every semester, the course instructor handling theoretical or practical courses would be developing course plans containing student activities to address in-syllabus and beyond syllabus topics. In addition to such activities, routine activities like lab record evaluation, written assignment evaluation, and seminar evaluation need to be scheduled in the course plan. After scheduling such evaluation rubrics have to be designed to assess the student performance. The usual practices to publish such rubrics to students to make them aware of the assessment policy. The refinement process begins with a peer evaluation of the designed rubrics by a co-instructor or by a faculty who has handled the course on a previous occasion. After this first step of refinement, the rubrics are further refined by external stake-holders like alumni and students who are the target of assessment. After receiving feedback from stakeholders on criteria selected in rubrics, the scale of evaluation, and total score allotted, necessary changes are made in the rubrics. The redesigned rubrics are then published to ensure fair and consistent assessment.

\section{Results and discussions}

Rubrics have been designed for simple and complex activities. These rubrics have to be refined since a small mistake in evaluation can affect the academic performance of students. A sample rubrics designed initially by the course instructor for written assignments to be submitted in online mode are shown below.

\begin{tabular}{|c|c|c|}
\hline \multirow{3}{*}{$\begin{array}{l}\text { Criteria } 1 \\
\text { Completeness } \\
\text { of } \\
\text { Submission } \\
\text { (5 points) } \\
\text { Indicates the } \\
\text { assignment is } \\
\text { complete with } \\
\text { all details, } \\
\text { parameters. }\end{array}$} & $\begin{array}{l}\text { Exemplary } \\
\text { The instructions have been } \\
\text { read carefully and all parts of } \\
\text { the question are addressed } \\
\text { well. }\end{array}$ & 5 \\
\hline & $\begin{array}{l}\text { Average } \\
\text { The instructions have been } \\
\text { read but all parts of the } \\
\text { question are not fully } \\
\text { addressed. }\end{array}$ & 2.5 \\
\hline & $\begin{array}{l}\text { Needs Improvement } \\
\text { The instructions have not } \\
\text { been read carefully and some } \\
\text { parts of the question have not } \\
\text { been addressed. }\end{array}$ & 0.5 \\
\hline \multirow{3}{*}{$\begin{array}{l}\text { Criteria } 2 \\
\text { Technical } \\
\text { Solution } \\
\text { (8 points) } \\
\text { Indicates the } \\
\text { technical } \\
\text { details are } \\
\text { properly } \\
\text { mentioned } \\
\text { with circuit } \\
\text { diagrams, } \\
\text { operation and } \\
\text { waveform. }\end{array}$} & $\begin{array}{l}\text { Exemplary } \\
\text { The Solution includes the neat } \\
\text { circuit diagram with the } \\
\text { operation of the circuit. }\end{array}$ & 8 \\
\hline & $\begin{array}{l}\text { Average } \\
\text { The solution includes the } \\
\text { circuit diagram, but the circuit } \\
\text { diagram is not neat and } \\
\text { operation of the circuit is not } \\
\text { complete. }\end{array}$ & 4 \\
\hline & $\begin{array}{l}\text { Needs Improvement } \\
\text { The solution does not include } \\
\text { the circuit diagram and } \\
\text { operation of the circuit is not } \\
\text { complete. }\end{array}$ & 1 \\
\hline
\end{tabular}

Table 1a: Rubrics - Criteria $1 \& 2$

The criteria mentioned in Table 1a are designed to ensure the completeness of submitted assignments with the correct technical solution. Criteria 1 is aimed at making the learner to present his/her solution in a methodical manner after 
reading the complete question and its related instructions. These criteria will make the learner carefully read instructions and follow them in presenting a complete and detailed solution. Criteria 2 is aimed at ensuring the technical feasibility of the solution provided by the learner in any course on electrical and electronics engineering. The solution should comprise details of design, working principles, advantages, and limitations.

\begin{tabular}{|c|c|c|}
\hline \multirow{3}{*}{$\begin{array}{l}\text { Criteria } 3 \\
\text { Presentation } \\
\text { (4 points) } \\
\text { Indicates the } \\
\text { assignment } \\
\text { presentation } \\
\text { skills, the order } \\
\text { of writing the } \\
\text { assignment } \\
\text { and } \\
\text { handwriting } \\
\text { skills }\end{array}$} & $\begin{array}{l}\text { Exemplary } \\
\text { The written assignment is } \\
\text { clearly presented, with neat } \\
\text { handwriting and all figures } \\
\text { neatly drawn }\end{array}$ & 4 \\
\hline & $\begin{array}{l}\text { Average } \\
\text { The written assignment is } \\
\text { fairly presented, handwriting } \\
\text { is not neat and figures are not } \\
\text { neatly drawn }\end{array}$ & 2 \\
\hline & $\begin{array}{l}\text { Needs Improvement } \\
\text { The written assignment is } \\
\text { poorly presented, handwriting } \\
\text { is not neat and figures are not } \\
\text { neatly drawn }\end{array}$ & 1 \\
\hline \multirow{3}{*}{$\begin{array}{l}\text { Criteria } 4 \\
\text { Promptness } \\
\text { (3 points) } \\
\text { Indicates } \\
\text { submission } \\
\text { details }\end{array}$} & $\begin{array}{l}\text { Exemplary } \\
\text { The assignment was } \\
\text { submitted in advance before } \\
\text { the due date of submission. }\end{array}$ & 3 \\
\hline & $\begin{array}{l}\text { Average } \\
\text { The assignment was } \\
\text { submitted on the due date of } \\
\text { submission. }\end{array}$ & 1.5 \\
\hline & $\begin{array}{l}\text { Needs Improvement } \\
\text { The assignment was } \\
\text { submitted after the due date of } \\
\text { submission. }\end{array}$ & 0 \\
\hline
\end{tabular}

Table 1b: Rubrics - Criteria 3 \& 4

Criteria 3 is aimed at improving the presentation skills of students in a written assignment and may be modified to suit the requirements of a seminar or project evaluation. This criterion deals with handwriting skills for legible reading, sequencing of figures with neat labels, and line spacing with margins that enhance readability. Criteria 4 is aimed at inculcating punctuality and professional etiquette in students. Students generally tend to submit the assignment during the last minute of the deadline arising suspicions of plagiarism. To overcome this problem the course instructor has designed a rubric to encourage students to submit their assignment before the last date of submission. The above rubrics were peer-reviewed and were consolidated by alumni stake-holders. It was then put to test by publishing it for refinement to the target student group. A group of 188 students voluntarily participated in an online survey designed for collecting feedback on the above rubrics. The students were given a time period of three days to evaluate the above rubrics and to suggest certain changes in design criteria, the scale of evaluation, and points assigned for each criterion. Students from the second, third, and final year of electrical and electronics engineering, St Joseph Engineering College, participated in the online survey. The survey form was designed after peer evaluation and an online forum was chosen to display the rubrics and the ensuing queries.

The details of queries designed to get the student response on the rubrics listed in Table 1a and Table $1 \mathrm{~b}$ are given here. Students were asked whether they have been assessed using appropriate rubrics in any of the courses in the earlier semesters. In response to this query, $66 \%$ of the students responded by saying 'yes' and $34 \%$ responded by saying 'No'.

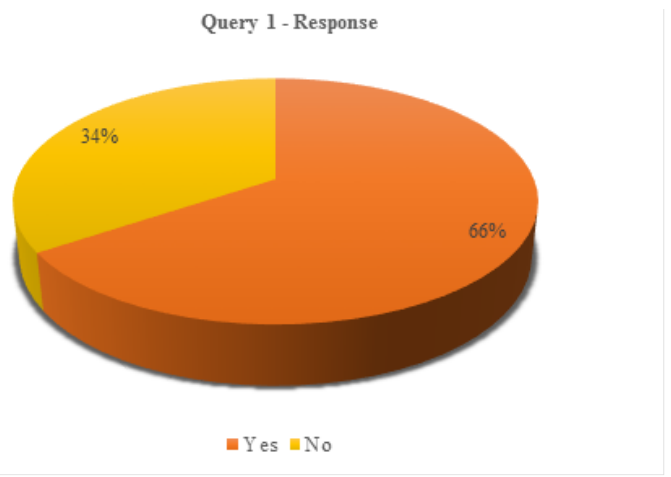

Figure 2: Response to Query 1

The second query was aimed at getting student responses on the criteria of completeness with options such as 'Doesn't matter to me', 'unsure', 'agree', 'any other'. If students chose the option 'any other', they were asked to provide suggestions for change in the online survey form.

Criteria I - Completeness of Submission

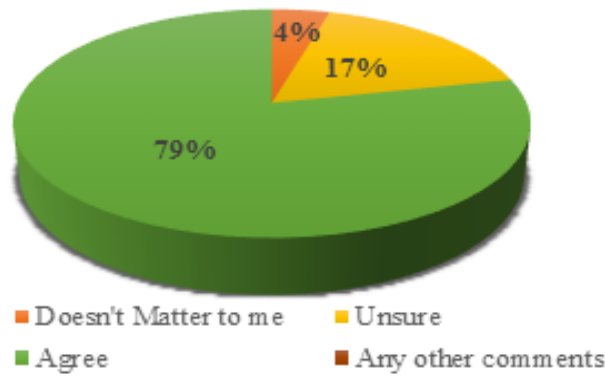

Figure 3: Response to Query 2

Since over $80 \%$ of the students seem to agree with the criteria of completeness with its description and assigned scale, no changes were made to these criteria by the course instructor.

Query 3 was aimed at getting student feedback on criteria 2 which is on the technical solution of the assignment. 


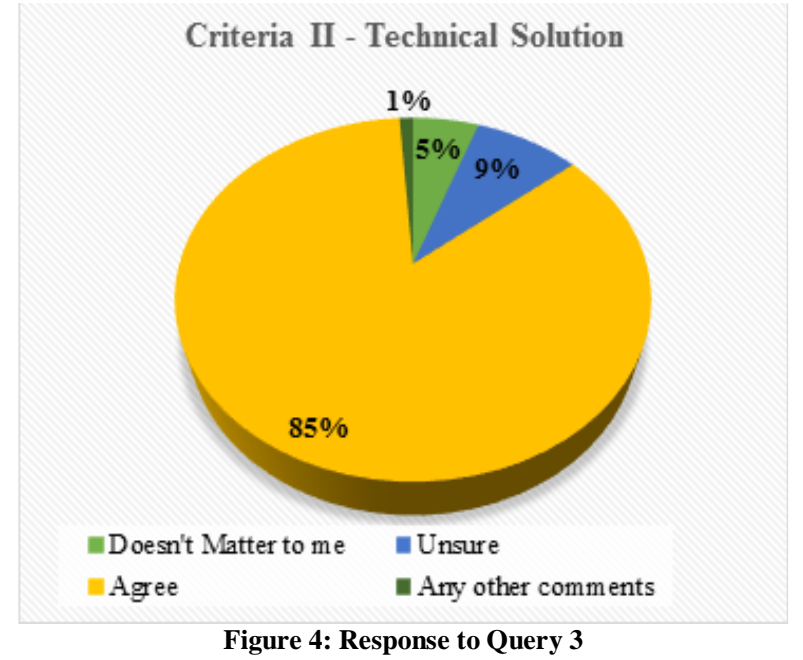

A substantial number of students have agreed that the diagrams and technical solutions have to be sequenced and labeled properly. Hence the criteria of the technical solution are retained in its present form by the course instructor.

The fourth query is aimed at getting feedback from students on the third criteria of presentation.

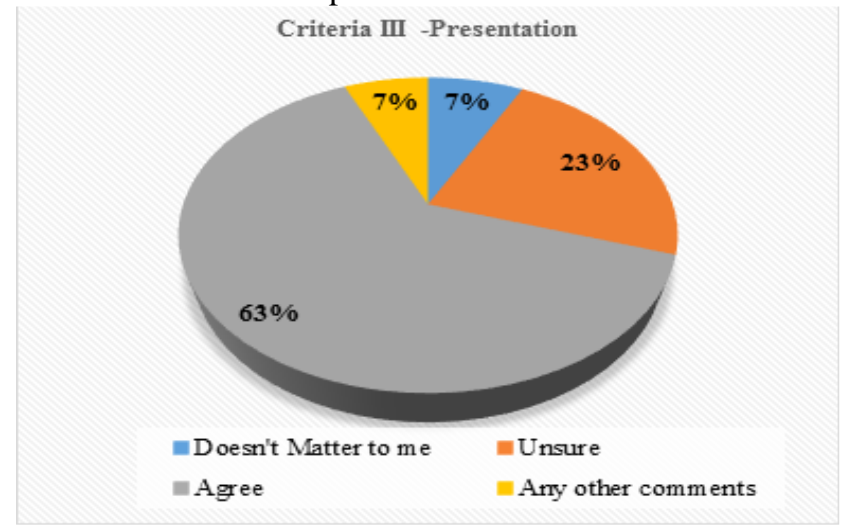

Figure 5: Response to Query 4

A substantial number of students have requested for a minor change in the rubrics description with less weightage given to handwriting skills.

The fifth query is aimed at getting feedback from students on the fourth criteria of promptness.

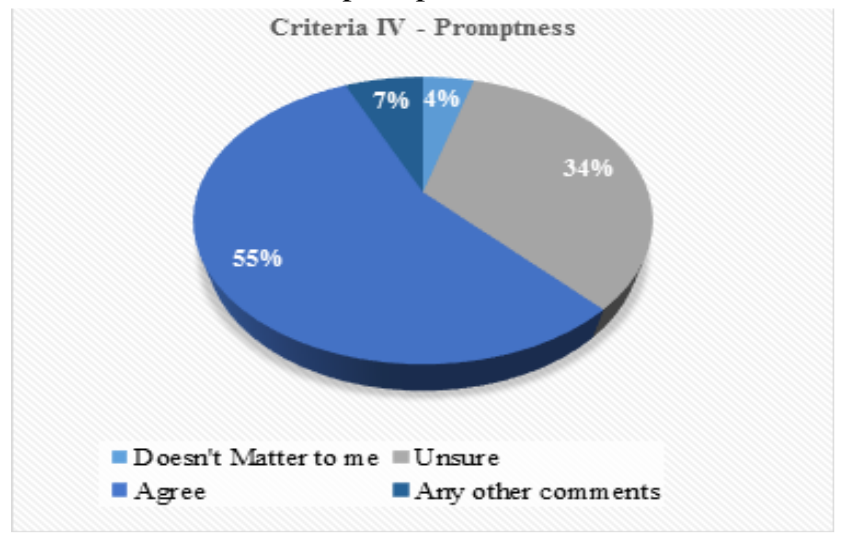

Figure 6: Response to Query 5

A substantial number of students have requested a change in the top scale of these criteria. The reasons given were that the students couldn't upload the online assignments before the deadline due to technical and connectivity issues.
It has been observed that approximately $40 \%$ of the students taking the survey required minor changes for criteria $3 \& 4$ related to presentation and promptness which are qualitative rubrics.

\section{Conclusion}

Fair and consistent assessment is a key factor to strengthen student-teacher relationships. The most important stakeholder in any assessment process is the student undergoing the test/evaluation. The opinion of these students along with peer opinion and feedback from alumni is essential in confirming the validity and robustness of assessment rubrics. It has been observed from survey-based statistical analysis that the students tend to agree with quantitative criteria in assessment rubrics such as completeness and technical solution in assignment submission. The students (approximately 30 to $40 \%$ ) tend to have dissatisfaction over qualitative criteria such as presentation and promptness of assignment submissions. The suggested relaxations such as the extension of submission deadlines for valid reasons and small errors in presentation due to handwriting or drawing skills of students were incorporated in the refined rubrics. The refined rubrics although satisfied with student suggestions, the instructor continued to have the freedom on providing valuable comments/ suggestions to students on better time management and handwriting skill improvement. This paper has worked on the refinement process of assessment rubrics of online written assignments and can be extended to other rubrics for assessing mini projects, seminars, debates, group discussions, Lab work, and many others.

\section{Acknowledgement}

The authors of the paper would like to acknowledge the support and guidance provided by the Management of St Joseph Engineering College, Mangaluru for executing the components of this work. We would also like to express our gratitude to IUCEE for its certification program which has motivated us to pursue Engineering Education Research.

\section{References}

B. Surendra Reddy (2015), Rubric Based Individual Itemized Assessment of Academic Projects, Journal of Engineering Education Transformations, ISSN 2349-2473, eISSN 2394-1707.

Dr. Shreeranga Bhat et al (2020), Effective Deployment of Outcome Based Education: Strategies based on Motivational Models, Journal of Engineering Education Transformations, Volume 33, January 2020, Special issue, eISSN 2394-1707.

S.B. Sangle et al (2020), Incorporating E-assessment tools in teaching for effective and authentic assessment, Journal of Engineering Education Transformations, Volume 33, January 2020, Special issue, eISSN 2394-1707.

Smt. Soniya Agrawal and Dr. Chandasree Das (Special Issue Jan. 2018), A comparative study on rubrics and its impact on program outcomes for the project work of under graduate program, Journal of Engineering Education Transformations, eISSN 2394-1707. 